\title{
Bioefficacy of some insect growth regulators and plant extracts against mosquito larvae of Aedes aegypti
}

\author{
Al-Zahrani Mohamd R. ${ }^{1}$, Mahyoub Jazem A. ${ }^{1,2,}{ }^{*}$, Al-Ghamdi Khalid M. ${ }^{1}$ and Al-Solami Habeeb M. ${ }^{1}$ \\ ${ }^{1}$ Department of Biological Sciences, Faculty of Science, King Abdul-Aziz University, Jeddah, Saudi Arabia. \\ 2 IBB University, Ibb, Republic of Yemen.
}

Publication history: Received on 28 November 2018; revised on 29 December 2018; accepted on 08 January 2019

Article DOI: https://doi.org/10.30574/gscbps.2019.6.1.0148

\begin{abstract}
Susceptibility levels of Aedes aegypti mosquito larvae, collected from Al-Taif governorate, Saudi Arabia were evaluated against three insect growth regulators (IGRs) Diflox flowable, Baycidal and Sumilarv as well as three plant extracts Thevetia nerviifolia, Plumeria acuifolia and Lantana camara. According to values of IC 50 (concentration which to inhibit the emergence of $50 \%$ of adults), the IGR Diflox flowable $(0.0028 \mathrm{ppm})$ proved to be more effective against mosquito larvae of $A$. aegypti than Baycidal ( $0.0033 \mathrm{ppm})$ and Sumilarv $(0.047 \mathrm{ppm})$ by about 1.8 and 16.8 times, respectively. The change in the susceptibility level of the present mosquito larvae may be attributed to the differential mode of actions of the tested IGRs and its effective concentrations. On the other hand, the plant extract T. neriifolia proved to be more effective against A. aegypti larvae, followed by P. acuifolia and L. camara by about 1.3 and 3.7 folds, respectively. This was highly pronounced on the basis of IC $_{50}$ values obtained which were in respect 85.5 ppm, 108.7 ppm and 317.4 ppm. Variation in the susceptibility status of $A$. aegypt larvae is possibly due to differences in the nature of active components present in the test plant extracts and its effective concentrations. Generally, the tested IGRs and plant extracts exhibited promising larvicidal activity and can be used as alternatives for mosquito control.
\end{abstract}

Keywords: Aedes aegypti; Mosquito larvae; Insect growth regulators; Plant extracts

\section{Introduction}

Mosquitoes can transmit more diseases than any other group of arthropods and affect millions of people throughout the world. They act as vectors for several human diseases like malaria, yellow fever, dengue fever, chikungunya fever and filariasis in different parts of the world [1-2].

Mosquito control is critical for managing the spread of disease agents and is based primarily on the use of chemical insecticides. Drawbacks associated with widespread use of these conventional insecticides for mosquito control have not only resulted in attaining physiological resistance in mosquito strains but also caused long-term harmful effects on non-target organisms and other environmental components [3-4]. Therefore, more attention has been recently paid to the use of non-conventional insecticides such as bioinsecticides, insect growth regulators (IGRs) and plant extracts for controlling mosquito vectors around the world [5-8].

The aim of the current study is to evaluate the biological effects of three IGRs as well as three plant extracts on the developmental stages of $A$. aegypti, the primary vector of dengue fever in Taif governorate, Saudi Arabia.

\footnotetext{
${ }^{*}$ Corresponding author

E-mail address: jazem2009@gmail.com
} 


\section{Material and methods}

\subsection{Collection and rearing of mosquitoes}

Tests were performed on a field mosquito strain of Aedes aegypti raised from wild larvae, collected from Al-Taif governorate, Saudi Arabia, and had been maintained in the laboratory under controlled conditions of $27 \pm 1{ }^{\circ} \mathrm{C}$ and $70 \pm 5 \%$ R.H., with a photoperiod of $14 \mathrm{~h}: 10 \mathrm{~h}$ (L: D). The larvae were fed on powdered mixture of equal parts of biscuits, dried yeast and fat-free milk. The larvae were reared until pupation and adult emergence took place for maintaining the stock culture.

\subsection{Collection of plants and extraction}

Fresh larvae of T. neriifolia, P. acuifolia, and L. camara were collected from the plants grown in the garden of King Abdulaziz University, Jeddah. Leaves were properly cleaned, washed with distilled water and shade dried at room temperature. The dried leaves were powdered mechanical using commercial electrical stainless steel blander. Samples of powdered plant material each $30 \mathrm{gm}$ were loaded in Soxhelt apparatus and were extracted with ethanol. The extract was subjected to a rotary vacuum evaporator to collect the crude extract. The extracts were stored in air tight container at room temperature and kept in dark until used.

\subsection{IGRs tested}

Three IGRs were used: Diflox flowable 10\% SC (diflubenzuron), 1-(4-chlorophenyl)-3-(2,6-difluorobenzyl)- urea, INDIA Industrie Chimicale, Italy; Baycidal 25 WP (triflumron), benzamide-2-chloro-N- [(trifluoro methoxy) phenyl) amino) carbonyl], Bayer, Germany; Sumilarv 0.5G (Pyriproxyfen), 2-[1-methyl-2-(4-phenoxy) ethoxy] pyridine, Sumitomo Chem. Co., Japan.

\subsection{Preparation of stock solutions}

The stock solution of each IGR was prepared by adding $1 \mathrm{gm}$ (or $1 \mathrm{ml}$ ) of it to $99 \mathrm{ml}$ of distilled water. In the case of the plant extract, the stock solution was prepared by adding $1 \mathrm{gm}$ of it to $99 \mathrm{ml}$ of distilled water containing $0.5 \%$ trition X100 as an emulsifier to ensure complete solubility of the extract in water, Series of concentrations were prepared in distilled water.

\subsection{Larvicidal bioassay}

The standard method of WHO [9] was conducted to determine the susceptibility level of A. aegypti mosquito larvae to the tested IGRs and plant extracts. Treatments were carried out by exposing the early fourth instar larvae of $A$. aegypti to various concentrations of the tested compounds in groups of plastic cups containing $100 \mathrm{ml}$ of tap water. Five replicates of 20 larvae each per concentration, and so for control trials were set up. Cumulative mortalities of larvae and pupae were recorded daily. Live pupae were transferred to untreated water in new plastic cups for further observations, i.e., normal emergence, morphological abnormalities or death. Partially emerged adults or those found complete emerged but unable to leave the water surface were recorded separately but scored as dead ones. The percent mortalities in the treatments were recorded and compared with those of the control trials under the same conditions of tests. The biological effects of the tested compounds were expressed as the percentage of larvae that do not develop into successfully emerging adults, or the inhibition of adult emergence.

\subsection{Statistical analysis}

The SPSS software package was used for computing all larval mortality data including probit analysis, toxicity lines and statistical parametgers such as IG $_{50}$, IC 90 , slope and (Chi). Results with $\mathrm{P}<0.05$ were considered to be statistically significant.

\section{Results and discussion}

Percentage mortalities of $A$. aegypti larvae and inhibition of adult emergency following treatments with the effective concentrations of the tested IGRs and plant extracts are shown in Table $1 \& 2$ and illustrated by Fig. 1-3. In general, treatments with the effective concentrations of the IGRs Diflox flowable (0.001- 0.009 ppm), Baycidal (0.001- 0.01 ppm) and Sumilarv (0.01-0.15 ppm) caused in respect 10-36\%, 8-74\% and 12-51\% larval mortality. 8-33\%, 9-44\% and 14$42 \%$ larval mortality were also obtained when the $4^{\text {th }}$ instar larvae of $A$. aegypti were treated with the effective concentrations of the plant extracts T. neriifolia (60-160 ppm), P. acuifolia (80-180 ppm) and L. camara (100-900 ppm), respectively. However, as shown in Fig. 1, the biological effects of the test IGRs and plant extracts were often manifested 
by the formation of a type of larval-pupal intermediate. Some pupae were died before the adult emerged as albino pupa (unmelaninized pupa).
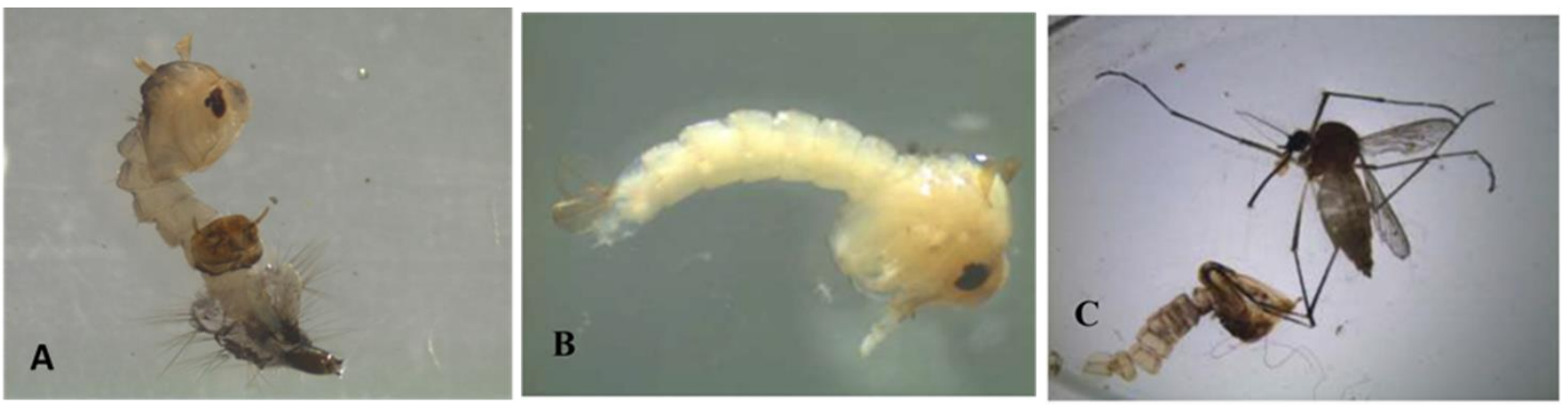

Figure 1 Abnormalities in the developmental stages of A. aegypti after larval treatments with the tested IGRs and plant extracts. A- Larval-pupal intermediate, B- Albino pupa (unmelaninized pupa) and C- Adult failed to emerg and attached in the pupal exuvium.

Most adults were emerged incompletely or left their tarsi attached in the pupal exuvia [10-11]. In other words, the results thus may confirm the unsuitability of larval mortality records as a criterion for evaluating the efficacy of such compounds as they more Juvenilizing effects than toxic mode of action [12]. Therefore, the biological effects of the present IGRs and plant extracts were expressed as the percentage of larvae that do not develop into successfully emerging adults or the inhibition of adult emergence [9].

Table 1 The biological effects of the tested IGRs on the developmental stages of $A$. aegypti

\begin{tabular}{|c|c|c|c|c|c|c|}
\hline \multirow[t]{2}{*}{ IGRs } & \multirow{2}{*}{$\begin{array}{l}\text { Effective } \\
\text { concentrations } \\
\text { (ppm) }\end{array}$} & \multirow{2}{*}{$\begin{array}{l}\text { Larval }^{a} \\
\text { mortality } \\
(\%)\end{array}$} & \multirow{2}{*}{$\begin{array}{l}\text { Inhibition }{ }^{b} \\
\text { of adult } \\
\text { emergence } \\
(\%)\end{array}$} & \multicolumn{3}{|c|}{ Statistical parameters } \\
\hline & & & & $\begin{array}{l}\mathrm{IC}_{50}(\mathrm{ppm}) \\
\text { (LL: HL)* }^{*}\end{array}$ & $\begin{array}{l}\text { IC90 (ppm) } \\
\text { (LL: HL)* }\end{array}$ & Slope \\
\hline $\begin{array}{l}\text { Diflox } \\
\text { flowable }\end{array}$ & 0.001-0.009 & $10-36$ & $25-91$ & $\begin{array}{l}0.0028 \\
(0.00024-0.0032)\end{array}$ & $\begin{array}{l}0.012 \\
(0.0098-0.016)\end{array}$ & 2.01 \\
\hline Baycidal & $0.001-0.010$ & $8-47$ & $14-94$ & $\begin{array}{l}0.0033 \\
(0.0029-0.0037)\end{array}$ & $\begin{array}{l}0.0098 \\
(0.0084-0.012)\end{array}$ & 2.69 \\
\hline Sumilarv & $0.01-0.15$ & $12-51$ & $17-90$ & $\begin{array}{l}0.047 \\
(0.041-0.054)\end{array}$ & $\begin{array}{l}0.21 \\
(0.16-0.29)\end{array}$ & 1.97 \\
\hline
\end{tabular}

${ }^{a}$ - Five replicates, 20 larvae each, ${ }^{b}$ Inhibition of adult emergence in control ranged from 2-4\% and ${ }^{*}$ - Fiducial limits of IC $C_{50}$ or IC $\mathrm{C}_{90}$.

Generally, the results represented in Table 1 indicated that larval treatments with the above effective concentrations of IGRs Diflox flowable, Baycidal and Sumilarv caused in respect $25-91 \%, 14-94 \%$ and $17-90 \%$ inhibition of adult emergence. According to values of $\mathrm{IG}_{50}$ (concentration which to inhibit the emergence of $50 \%$ of adults), Diflox flowable $(0.0028 \mathrm{ppm})$ proved to be the most effective IGR against $A$. aegypti, followed by Baycidal $(0.0033 \mathrm{ppm})$ and Sumilarv (0.047 ppm) by about 1.8 and 16.8 times, respectively (Fig. 2).

Variations in the susceptibility levels of $A$. aegypti against the test IGRs may be attributed to the differential mode of action of the present IGRs and its effective concentrations. Laboratory and field studies in this respect were carried out by several investigators using different formulations of IGRs against various mosquito species such as the IGR triflumuron against $C$. quinquefasciatus in polluted water [13]; The IGRs Diflubenzuron and Methoprone against $A$. aegypti [14]; the IGRs pyriproxyfen and Methoprene against $A$. albopictus and $C$. quinquefasciatus [15]; the IGR pyripoxyfen against $C$. quinqueasciatus in catch basins [16]; the IGR Halofenozide towards $C$. pipiens [17]. 


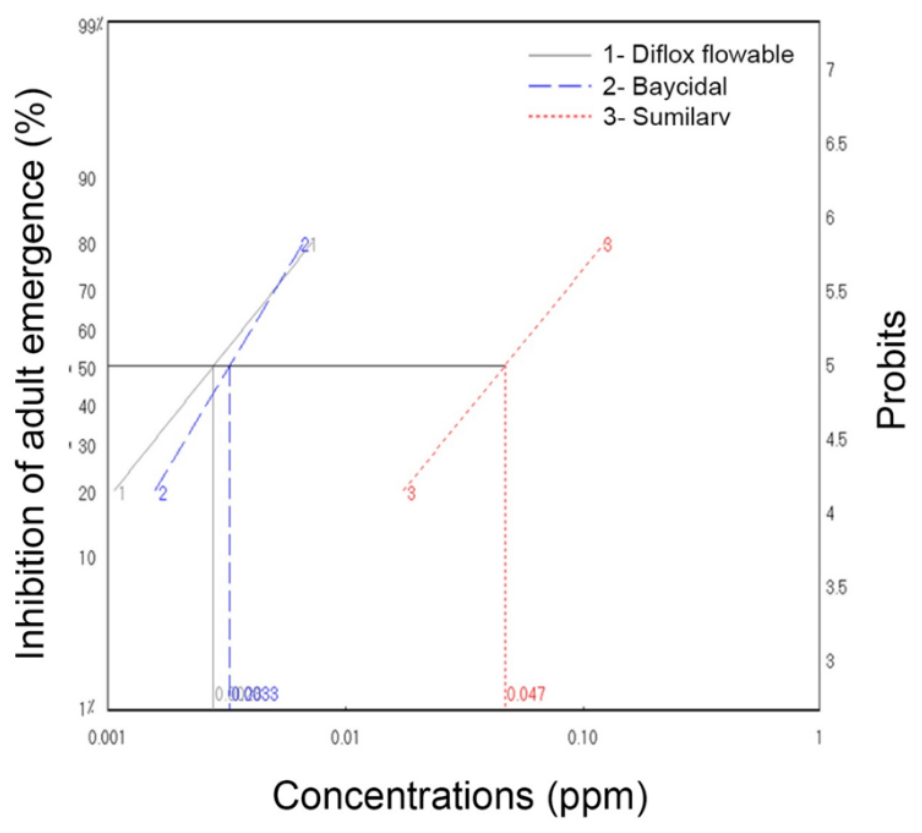

Figure 2 The relation between concentrations of the tested IGRs and the percentage of inhibition of adult emergence after treatment of $4^{\text {th }}$ instar larvae of $A$. aegypti

Table 2 The biological effects of the tested plant extracts on the developmental stages of $A$. aegypti

\begin{tabular}{|c|c|c|c|c|c|c|}
\hline \multirow{2}{*}{$\begin{array}{l}\text { Plant } \\
\text { extracts }\end{array}$} & \multirow{2}{*}{$\begin{array}{l}\text { Effective } \\
\text { concentrations } \\
\text { (ppm) }\end{array}$} & \multirow{2}{*}{$\begin{array}{l}\text { Larval }^{a} \\
\text { mortality } \\
(\%)\end{array}$} & \multirow{2}{*}{$\begin{array}{l}\text { Inhibition }^{b} \text { of } \\
\text { adult } \\
\text { emergence } \\
(\%)\end{array}$} & \multicolumn{3}{|c|}{ Statistical parameters } \\
\hline & & & & $\begin{array}{l}\text { IC } 50 \text { (ppm) } \\
\text { (LL: HL)* }\end{array}$ & $\begin{array}{l}\text { IC90 (ppm) } \\
\text { (LL: HL)* }\end{array}$ & Slope \\
\hline T. neriifolia & $60-160$ & $8-33$ & $21-93$ & $\begin{array}{l}85.5 \\
(80.7-90.2)\end{array}$ & $\begin{array}{l}146.8 \\
(135.1-164.1)\end{array}$ & 5.46 \\
\hline P. acuifolia & $80-180$ & $9-44$ & $20-95$ & $\begin{array}{l}108.7 \\
(103.1-114.2)\end{array}$ & $\begin{array}{l}178.6 \\
(164.1-201.1)\end{array}$ & 5.94 \\
\hline L. camara & $100-900$ & $14-42$ & $14-42$ & $\begin{array}{l}317.4 \\
(268.9-367.3)\end{array}$ & $\begin{array}{l}1517.1 \\
(1173.1-2187.9)\end{array}$ & 1.89 \\
\hline
\end{tabular}

$a$ - Five replicates, 20 larvae each, $b$ - Inhibition of adult emergence in control ranged from 2-4\% and * - Fiducial limits of IC S0 $_{50}$ IC $_{90}$

On the other hand, the results showed that larval treatments with the effective concentrations of the test plant extracts T. neriifolia, $P$. acuifolia and L. camara against $A$. aegypti caused in respect $21-93 \%, 20-95 \%$ and $21-86 \%$ inhibition of adult emergence (Table 2). As shown in Fig. 3, their IC 50 values were in respect 85.5 ppm, 108.7 ppm and 317.4 ppm. This means that mosquito larvae of $A$. aegypti were more susceptible to the plant extract T. neriifolia than $P$. acuifolia and L. camara by about 1.3 and 3.7 folds, respectively. It can be concluded that the change in the susceptibility status of A. aegypti mosquito larvae reflected by the inhibition of adult formation is possible due to variations in the nature of active ingredients present in plant extracts and its effective concentrations. Studies in this respect were conducted by several authors to evaluate the biological effects of different plant extracts against a wide spectrum of mosquito vectors [18-21]. They pointed out that most of these plant extracts have been reported to exhibited mosquito larvicidal activities and may be serve as suitable alternatives for mosquito control. However, long term follow-up studies are needed to evaluate the possible delayed effects of such compounds on some biological and behavioural aspects of mosquito vectors. 


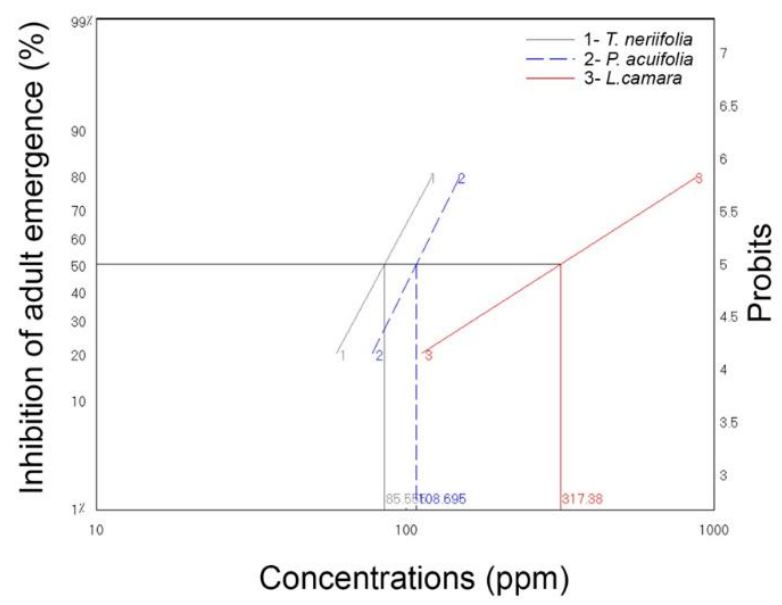

Figure 3 The relation between concentrations of the tested plant extracts and the percentage of inhibition of adult emergence after treatment of $4^{\text {th }}$ instar larvae of $A$. aegypti

\section{Conclusion}

It is evident from our results that treatment with the tested IGRs and plant extracts exhibited promising mosquito larvicidal effectiveness against $A$. aegypti and these compounds can be used to replace conventional insecticides for mosquito control. Compliance with ethical standards.

\section{Compliance with ethical standards}

\section{Acknowledgments}

The authors are indebted to the staff of Department of Biological Sciences, College of Science at king Abdulaziz Univ., Jeddah for their help and support during this research work.

\section{Disclosure of conflict of interest}

We have no conflicts of interest to disclose.

\section{References}

[1] WHO (2002). Dengue and Dengue haemorrhagic fever. Fact. Sheet No. 117. WHO, Geneva.

[2] WHO (2010). Centralized Information System Infectious Diseases (CISID) database.

[3] Al-Ghamdi KH, Saleh MS, Mahyoub JA and Al-Fifi ZI. (2009). Laboratory evaluation of the insect growth regulator dudim and the plant extract neem oil against Culex pipiens mosquitoes with reference to its side effects on aquatic nontarget organisms. Biosciences, Biotechnology Research Asia, 6(2), 509-512.

[4] El-Heneidy A. (2018). Laboratory evaluation of the effect of insecticides on non-target organisms: 2-the egg parasitoid, Trichogramma evanescens West (Hymenoptera: Trichogammatidae). Egyptian Academic Journal of Biological Sciences, 11(3), 35-44.

[5] Suman DS, Wang Y, Bilgrami AL and Gaugler R. (2013). Ovicidal activity of three insect growth regulators against Aedes and Culex mosquitoes. Acta Tropica, 128(1), 103-109.

[6] Rathy MC, Sajith U, Harilal CC. (2015). Plant diversity for mosquito control: A preliminary study. Int J Mosq Res, 2(1), 29-33.

[7] Amira K, Touahria Chouaib NE, Boudjelida H. (2018). Laboratory study of larvicidal efficacy of a local plant Hertia cheirifolia against the most abundant mosquito species, in Algeria. Journal of Entomology and Zoology Studies, 6(1), 258-262. 
[8] Lau KW, Chen CD, Lee HL, Low VL and Sofian-Azirun M. (2018). Bioeficacy of insect growth regulators against Aedes albopictus and Culex quinqueasciatus (Diptera: Culicidae) from Sarawak, Malaysia: A statewide Survey. Journal of economic entomology, 111(3), 1388-1394.

[9] WHO (2005). Guidelines for laboratory and field testing of mosquito larvicides. WHO/CDS/WHOPES/CDPP/13.

[10] Saleh MS, Gaaboub IA and Kassem SM. (1981). Larvicidal effectiveness of three controlled-release formulations of Dursban and Dimilin on Culex pipiens L. and Aedes aegypti (L.). The Journal of Agricultural Science, 97(1), 8796.

[11] Mahyoub JA, Hawas UW, Al-Ghamdi KM, Aljameeli MM, Shaher FM, Bamakhrama MA and Alkenani NA. The biological effects of some marine extracts against Aedes aegypti (L.) mosquito vector of the dengue fever in Jeddah Governorate, Saudi Arabia. J. Pure Appl. Microbiol, 10(3), 1949-1956.

[12] Saleh MS, Wright RE. (1989). Effects of the IGR cyromazine and the pathogen Bacillus thuringiensis var. israelensis on the mosquito Aedes epacticus. Journal of Applied Entomology, 108(1-5), 381-385.

[13] Batra CP, Mittal PK, Adak T and Ansari MA. (2005). Efficacy of IGR compound Starycide 480 SC (Triflumuron) against mosquito larvae in clear and polluted water. Journal of vector borne diseases, 42(3), 109-116.

[14] da Silva JJ, Mendes J and Lomônaco C. (2009). Effects of sublethal concentrations of diflubenzuron and methoprene on Aedes aegypti (Diptera: Culicidae) fitness. International Journal of Tropical Insect Science, 29(1), 17-23.

[15] Khan GZ, Khan I, Khan IA, Salman M, Ullah K. (2016). Evaluation of different formulations of IGRs against Aedes albopictus and Culex quinquefasciatus (Diptera: Culicidae). Asian Pacific Journal of Tropical Biomedicine, 6(6), 485-491.

[16] Mian LS, Dhillon MS, Dodson L. (2017). Field evaluation of pyriproxyfen against mosquitoes in catch basins in Southern California. Journal of the American Mosquito Control Association, 33(2), 145-147.

[17] Bouaziz A, Amira K, Djeghader N, Aissaoui L and Boudjelida H. (2017). Impact of an insect growth regulator on the development and the reproduction potency of mosquito. J. Ent. And Zoo. Studies, 5(3), 1662-1667.

[18] Mohankumar TK, Shivanna KS and Achuttan VV. (2016). Screening of methanolic plant extracts against larvae of Aedes aegypti and Anopheles stephensi in Mysore. Journal of arthropod-borne diseases, 10(3), 303.

[19] Ashwini U and Asha S. (2017). Larvicidal activity of natural products against mosquito species: A review. International Journal of ChemTech Research, 10(5), 875-878.

[20] Hari I and Mathew N. (2018). Larvicidal activity of selected plant extracts and their combination against the mosquito vectors Culex quinquefasciatus and Aedes aegypti. Environmental Science and Pollution Research, 25(9), 9176-9185.

[21] Thongwat D, Chokchaisiri R, Ganranoo L, Bunchu N. (2018). Larvicidal efficacy of crude and fractionated extracts of Dracaena loureiri against Aedes aegypti, Aedes albopictus, Culex quinqueasciatus and Anopheles minimus mosquito vectors. Asian Pacific Journal of Tropical Biomedicine, 8(5), 273.

\section{How to cite this article}

Al-Zahrani MR, Mahyoub JA, Al-Ghamdi KM and Al-Solami HM. (2019). Bioefficacy of some insect growth regulators and plant extracts against mosquito larvae of Aedes aegypti. GSC Biological and Pharmaceutical Sciences, 6(1), 01-06. 